\title{
Analisis Faktor-Faktor yang Mempengaruhi Niat Pembelian Sayur Organik (Kasus Ibu Rumah Tangga di Kota Malang)
}

\section{Analysis of Factors That Influence The Intention to Purchase Organik Vegetables (Case of Housewife in Malang City)}

\author{
Rika Ismania Susanti ${ }^{1 *}$, Abdul Wahib Muhaimin ${ }^{2}$, Hery Toiba ${ }^{2}$ \\ ${ }^{1}$ Program Pascasarjana, Fakultas Pertanian, Universitas Brawijaya, JL. Veteran, Malang 65145, \\ Indonesia \\ ${ }^{2}$ Jurusan Sosial Ekonomi, Fakultas Pertanian, Universitas Brawijaya, JL. Veteran, Malang 65145, \\ Indonesia
}

Received: 9 September 2018; Revised: 24 September 2018; Accepted: 1 December 2018

\begin{abstract}
ABSTRAK
Makanan organik diseluruh dunia semakin populer dan konsumen makanan organik sedang meningkat. Namun, informasi tentang perilaku konsumen terhadap pembelian makanan organik khususnya sayur organik di negara berkembang seperti di Indonesia, masih sangat kurang. Sehingga, tujuan penelitian ini yaitu meneliti faktor-faktor apasaja yang mempengaruhi niat pembelian sayur organik khususnya ibu rumahtangga. Lokasi penelitian dilakukan di Kelurahan Sawojajar yang dipilih secara purposive. Sampel penelitian merupakan ibu rumah tangga sampel berjumlah 120 orang yang dipilih secara purposive. Metode analisis data menggunakan Stuctural Equation Modeling (SEM) dengan program AMOS. Hasilnya menunjukkan, pengetahuan dan informasi pada label sayur organik berpengaruh positif dan signifikan terhadap sikap, kemudian ketiga variabel theory planned behavior yaitu sikap, norma subjektif dan persepsi kontrol perilaku juga terbukti berpengaruh positif dan signifikan terhadap niat pembelian ibu rumahtangga pada sayur organik.
\end{abstract}

Keywords: sayur organik; niat pembelian

\section{ABSTRACT}

Organic foods throughout the world are increasingly popular and consumers of organic food are on the rise. However, information about consumer behavior towards purchasing organic food, especially organic vegetables in developing countries such as Indonesia, is still lacking. So, the purpose of this study is to examine what factors influence the intention to purchase organic vegetables. The research sample is a housewife sample of 120 people selected purposively. The data analysis method uses Stuctural Equation Modeling (SEM) with the AMOS program. The results showed that knowledge and information on organic vegetable labels had a positive and significant effect on attitudes, then the three variables of planned planned behavior namely attitudes, subjective norms and behavioral control perceptions also proved to have a positive and significant effect on the purchase intention of housewives on organic vegetables.

Keywords: organic vegetables; purchasing intentions

\section{How to cite:}

Susanti, R. I., Muhaimin, A. W., \& Toiba, H. (2018). Analisis Faktor-Faktor yang Mempengaruhi Niat Pembelian Sayur Organik ( Kasus Ibu Rumah Tangga di Kota Malang ). HABITAT, 29(3), 122-128. https://doi.org/10.21776/ub.habitat.2018.029.3.15

\section{Pendahuluan}

Kesadaran masyarakat atas efek yang ditimbulkan oleh bahan-bahan kimia seperti, pestisida, pupuk kimia dan hasil rekayasa genetika yang digunakan untuk meningkatkan hasil produksi pertanian, telah mengubah pola konsumsi atau gaya hidup masyarakat menjadi lebih selektif dan bijak dalam memilih produk yang akan dikonsumsinya (Teng and Wang 2015). Hal ini membuat masalah keamanan pangan dan 
ramah lingkungan menjadi isu yang terus berkembang dalam industri pangan (Chan 2001). Perbaikan mutu ini mendorong masyarakat diberbagai negara mulai meninggalkan produkproduk pangan yang berbahan kimia dan mulai beralih kepada produk-produk pangan organik (Teng and Wang 2015); (Priambodo and Najib 2014).

Berdasarkan data pasar organik tahun 2015 yang diterbitkan oleh (IFOAM 2017) mengemukakan bahwa pasar organik terbesar diduduki oleh negara-negara maju yaitu negara Amerika Serikat, Jerman, Perancis, dan China. Perkembangan pasarnya setiap tahun sekitar $20 \%$. Sedangkan untuk negara-negara berkembang, khususnya Indonesia menurut (AOI 2015) sebesar 5\% dengan nilai penjualan 10 miliar. Di Indonesia pertanian organik pertama kali diperkenalkan tahun 1984 dengan pengembangan usahtani sayur organik. Menurut survei yang dilakukan oleh (AOI 2017) pertumbuhan luas lahan dan produksi sayur organik tahun 2012-2015 mengalami penurunan. Menurut (Mayrowani 2016); (Syukur 2016) terdapat berbagai kendala yang dihadapi produsen sayur organik yaitu salah satunya belum ada kepastian pasar, sehingga petani enggan untuk memproduksi komoditas tersebut. Terkait konsumsi organik di Indonesia, dari hasil survey yang dilakukan oleh Yayasan Lembaga Konsumen Indonesia, 2013 nampak bahwa konsumsi organik di dalam negeri masih tergolong rendah.

Literatur-literatur mengenai konsumsi produk pangan organik, telah banyak yang meneliti mengenai faktor-faktor apa saja yang mempengaruhi niat pembelian terhadap produk pangan organik. Hasil penelitian yang dilakukan (Maichum, Parichatnon, and Peng 2017) di negara Thailand dengan responden 412 konsumen yang berumur diatas 18 tahun, terdapat tiga faktor yang mempengaruhi niat pembelian pangan organik yaitu sikap, norma subjektif dan persepsi kontrol perilaku konsumen. (Teng and Wang 2015) dalam penelitiannya yang dilakukan pada 693 konsumen pangan organik di Taiwan menunjukkan bahwa niat pembelian pangan organik dipengaruhi oleh sikap dan norma subjektif, sedangkan untuk sikap positif konsumen sendiri dipengaruhi oleh dua faktor

\footnotetext{
*) Penulis Korespondensi.

E-mail: Rikaismania26@gmail.com

Telp: +62-821-42719871
}

yaitu pengetahuan dan informasi pada label pangan organik.

Penelitian mengenai niat pembelian pangan organik telah banyak dilakukan, seperti yang dilakukan oleh (Magistris, Tiziana and Gracia 2008); (Maichum et al. 2017); (Tarkiainen and Sundqvist 2005); (Kim and Chung 2011); (Kalafatis et al. 1999); (Dean, Raats, and Shepherd 2008); (Teng and Wang 2015). Namun, penelitian mengenai niat pembelian pangan organik dengan menggunakan theory planned behavior dengan menambahkan dua variabel yaitu pengetahuan organik dan informasi pada label sebagai atesenden sikap belum pernah dilakukan di Indonesia dan rata-rata responden pada penelitian sebelumnya masih bersifat general yaitu konsumen pangan organik yang berumur diatas 18 tahun. Namun, pada penelitian ini responden yang diteliti berfokus pada ibu rumah tangga, dikarenakan menurut (Bourlakis and Weightman 2011) pada keputusan pembelian khususnya makanan, seorang ibu memegang peranan besar dalam pembelanjaan makanan dan seorang ibu sering bertindak dalam mengenalkan produk-produk baru pada anggota keluarganya, membuat pilihan yang mengakomodasi keinginan dan preferensi pasangan mereka dan keluarganya. Sehingga, penelitian ini bertujuan untuk meneliti mengenai bagaimana pengaruh pengetahuan dan informasi pada label sayur organik terhadap sikap, serta bagaimana sikap, norma subjektif dan persepsi kontrol perilaku terhadap niat pembelian sayur organik ibu rumahtangga.

\section{a. Tinjauan Literatur dan Hipotesis Penelitian}

Theory of Planned Behavior

merupakan model pengembangan dari Theory of Reasoned Action (TRA), dimana faktor-faktor penentu suatu perilaku adalah gabungan dari sikap terhadap perilaku tersebut (attitude towards the behavior), norma subjektif (subjective norms), dan persepsi kontrol perilaku yang dirasakan (perceived behavior control) oleh individu (Ajzen 2008)

(Magistris, Tiziana and Gracia 2008) menyatakan bahwa peningkatan pengetahuan organik sangat penting untuk meningkatkan konsumsi makanan organik, karena pengetahuan makanan organik sangat mempengaruhi sikap konsumen terhadap makanan organik. Dari uraian tersebut dapat dikemukakan hipotesis sebagai berikut : 


\section{b. H1 : Pengetahuan organik berpengaruh positif terhadap sikap.}

Menurut (Teng and Wang 2015) menunjukkan bahwa pelabelan organik memberikan sinyal berkualitas kepada konsumen, dan merupakan alat penting untuk membantu mereka mengidentifikasi dan mengembangkan sikap positif terhadap makanan organik Dari uraian tersebut dapat dikemukakan hipotesis sebagai berikut :

\section{c. H2 : informasi pada label sayur organik berpengaruh positif terhadap sikap}

Penelitian tentang konsumsi makanan organik telah mengkonfirmasi terdapat pengaruh positif dan signifikan sikap konsumen terhadap niat membeli (Magistris, Tiziana and Gracia 2008); (Maichum et al. 2017); (Tarkiainen and Sundqvist 2005); (Kim and Chung 2011); (Kalafatis et al. 1999); (Dean et al. 2008); (Teng and Wang 2015). Dari uraian tersebut dapat dikemukakan hipotesis sebagai berikut :

\section{d. $\mathrm{H3}$ : Sikap berpengaruh positif terhadap niat pembelian sayur organik}

Penelitian-penelitian sebelumnya tentang niat beli produk organik mengidentifikasi terdapat pengaruh yang positif dan signifikan norma subyektif terhadap niat pembelian makanan organik (Magistris, Tiziana and Gracia 2008); (Maichum et al. 2017); (Tarkiainen and Sundqvist 2005); (Kim and Chung 2011); (Kalafatis et al. 1999); (Dean et al. 2008); (Teng and Wang 2015). Dari uraian tersebut dapat dikemukakan hipotesis sebagai berikut :

\section{e. H4 : norma subjektif berpengaruh positif terhadap niat pembelian sayur organik}

Penelitian sebelumnya mengidentifikasi terdapat pengaruh yang positif dan signifikan persepsi kontrol perilaku terhadap niat pembelian makanan organik (Magistris, Tiziana and Gracia 2008); (Maichum et al. 2017); (Tarkiainen and Sundqvist 2005); (Kim and Chung 2011); (Kalafatis et al. 1999); (Dean et al. 2008); (Teng and Wang 2015). Dari uraian tersebut dapat dikemukakan hipotesis sebagai berikut:

\section{f. $\mathrm{H5}$ : persepsi kontrol perilaku berpengaruh positif terhadap niat pembelian sayur organik}

Definisi Operasional Penelitian:
1) Pengetahuan organik (X1) adalah persepsi responden mengenai tingkat informasi yang dimiliki responden mengenai sayur organik. Diukur dengan dua indikator yang di adobsi dari (Teng and Wang 2015); (Magistris, Tiziana and Gracia 2008) yaitu memiliki pengetahuan luas mengenai sayur organik (X1.1) dan memahami tanda atau ciri dari sayur organik (X2).

2) Informasi pada label sayur (X2) organik adalah Persepsi responden terhadap informasi yang diberikan pada label sayur organik. Diukur dengan tiga indikator yang diadobsi dari (Teng and Wang 2015) yaitu, informasi yang dipercaya (X2.1), informasi yang cukup (X2.2), informasi yang relevan (X2.3).

3) Norma subjektif (X3) adalah Keyakinan atau persepsi responden tentang tingkat tekanan sosial yang terkait dengan pembelian makanan organik. Diukur dengan tiga indikator yang diadobsi dari(Teng and Wang 2015); (Maichum et al. 2017); (Tarkiainen and Sundqvist 2005) yaitu keluarga (X3.1), Teman dekat (X3.2), dan media (X3.3).

4) Persepsi kontrol perilaku (X4) adalah Persepsi responden terhadap faktor-faktor yang mempermudah atau mempersulit minat pembelian sayuran organik. Diukur dengan dua indikator yang diadobsi dari (Maichum et al. 2017); (Kim and Chung 2011) yaitu kemudahan dalam mendapatkan sayur organik (X4.1) dan kemampuan membeli sayur organik (X4.2).

5) Sikap (Z) adalah Penilaian responden baik positif maupun negatif terhadap produk sayuran organik dibandingkan dengan sayur konvensional. Diukur dengan tiga indikator yang diadobsi dari (Magistris, Tiziana and Gracia 2008); (Maichum et al. 2017); (Tarkiainen and Sundqvist 2005); (Kim and Chung 2011); (Kalafatis et al. 1999); (Dean et al. 2008); (Teng and Wang 2015) yaitu kesehatan (Z1.1), keamanan (Z1.2) dan kualitas (Z1.3).

6) Niat pembelian sayur organik (Y) adalah Rencana, akan atau ekspresi keinginan responden untuk melakukan pembelian sayur organik. Diukur dengan tiga indikator yang diadobsi dari (Magistris, Tiziana and Gracia 2008); (Maichum et al. 
2017); (Tarkiainen and Sundqvist 2005); (Kim and Chung 2011); (Kalafatis et al. 1999); (Dean et al. 2008); (Teng and Wang 2015) yaitu berencana akan beralih membeli sayur organik (Y1.1), memutuskan akan membeli sayur organik (Y1.2) dan mengutamakan pilihan pada sayur organik (Y1.3).

\section{Metode Penelitian}

Penelitian ini menggunakan kuesioner dengan pertanyaan tertutup untuk mengumpulkan data penelitian dengan 5 skor jawaban yaitu skor 1 " sangat tidak setuju", 2 "tidak setuju", 3 "netral", 4 "setuju" dan 5 "sangat setuju". Lokasi penelitian dipilih secara purposive yaitu di Kelurahan Sawojajar Kecamatan Kedungkandang Kota Malang dengan pertimbangan kelurahan dan kecamatan tersebut merupakan kelurahan dan kecamatan yang memiliki jumlah rumah tangga terbanyak di Kota Malang dan memiliki klasifikasi keluarga yang beragam. Sampel pada penelitian ini dipilih secara quota sampling dengan kriteria ibu rumahtangga yang mengetahui tentang sayur organik dan pernah melihat label pada sayur organik. penelitian dengan menggunakan SEM, jumlah sampel yang sesuai adalah minimal 100 sampel. Besarnya penentuan sampel didasarkan pada pendapat (Ferdinand 2005) yang merekomendasikan bahwa besarnya sampel adalah 5 - 10 kali jumlah indikator. Pada penelitian ini terdapat 16 indikator dikali 7 maka besarnya sampel adalah 112 responden, namun kuesioner yang disebar dan dapat digunakan yaitu 120 kuesioner.

\section{Hasil dan Pembahasan}

Hasil pengolahan data yang dilakukan dapat dijelaskan sebagai berikut:

\section{a. Uji Normalitas Data}

Uji normalitas data digunakan sebagai syarat untuk emngolah data menggunakan metode pendugaan Maximum Likelihood (ML). Terpenuhinya normalitas data dapat menghindari bias dan ketidak efisienan hasil. Uji normalitas diukur dengan menggunakan kriteria critical ratio, hasil CR dinyatakan normal jika $<1,96$. Berdasarkan hasil olahan data penelitian dibandingkan dengan kriteria tersebut maka dapat disimpulkan bahwa distribusi data adalah tidak normal, secara multivariate dikarenalan hasil pada CR yaitu sebesar 7,751 yaitu nilai CR lebih besar dari 1,96. Namun, secara Dalil Limit Pusat
(Limit Central Theorem) menyatakan bahwa asumsi normalitas tidak terlalu kritis untuk sampel yang besar diatas 100, maka statistik dari sampel mendekati distribusi normal, walaupun populasi dari mana sampel tersebut diambil tidak berdistribusi normal (Solimun 2003).

\section{b. Uji Outlier}

Salah satu evaluasi outliers dilakukan secara multivariate yaitu dengan menggunakan jarak Mahalanobis untuk tiap-tiap observasi. Kriteria yang digunakan adalah berdasarkan nilai Chi-Square pada tingkat derajat kebebasasn (degree of freedom) tertentu dan pada tingkat signifikansi (alpha) tertentu yaitu $<110,898$ (chisquare table pada DF 88). Hasil penelitian ini menunjukkan bahwa nilai jarak mahalobis terbesar yaitu 74 sebesar 48,654 yang berarti $<110,898$ menjelaskan bahwa tidak terdapat outliers pada sampel pengamatan.

\section{c. Uji Model Pengukuran}

Metode yang digunakan yaitu Confirmatory Factor Analysis, Evaluasi terhadap validitas dari model pengukuran dapat dilakukan dengan melihat hasil estimasi muatan-muatan faktornya. Sedangkan evaluasi terhadap reliabilitas dari model pengukuran dalam SEM dapat menggunakan composite reliability measure.

Tabel 1. Hasil uji model pengukuran

\begin{tabular}{clrc}
\hline $\begin{array}{c}\text { Variabel } \\
\text { Laten }\end{array}$ & Indikator & $\begin{array}{r}\text { Loading } \\
\text { Factors }\end{array}$ & $\begin{array}{c}\text { Construct } \\
\text { Reability }\end{array}$ \\
\hline X1 & X1.1 & 0,925 & 0,969 \\
& X1.2 & 0,939 & \\
X2 & X2.1 & 0,719 & 0,795 \\
& X2.2 & 0,930 & \\
& X2.3 & 0,579 & \\
X3 & X3.1 & 0,876 & 0,839 \\
& X3.2 & 0,789 & \\
& X3.3 & 0,721 & \\
X4 & X4.1 & 0,687 & 0,922 \\
& X4.2 & 0,966 & \\
Z & Z1.1 & 0,807 & 0,842 \\
& Z1.2 & 0,900 & \\
& Z1.3 & 0,683 & \\
Y & Y1.1 & 0,821 & 0,868 \\
& Y1.2 & 0,851 & \\
& Y1.3 & 0,815 & \\
\hline
\end{tabular}

Dari hasil diatas dinyatakan bahwa seluruh indikator memiliki loading factor $\geq 0,50$ (Valid). Dengan demikian dapat disimpulkan bahwa validitas semua variabel-variabel manifes 
(indikator) terhadap variabel latennya adalah baik. Sedangkan dari hasil perhitungan reliabilitas menunjukkan bahwa semua nilai Cronbach Reliability (CR) $\geq 0,70$ (Reliabel), dengan demikian dapat disimpulkan bahwa semua variabel-variabel laten tersebut memiliki reliabilitas yang baik.

\section{d. Uji Ketepatan Model Goodness of Fit (GOF)}

Uji kecocokan ini ditujukan untuk mengevaluasi secara umum derajat kecocokan atau Goodness of Fit (GOF) antara data dengan model. Pada hasil analisis pertama hasilnya menunjukkan bahwa nilai GOF masih terdapat nilai yang poor fit atau tidak baik, sehingga dilakukan modifikasi model dengan melihat rekomendasi dari modification indices, setelah melaui serangkaian uji coba modifikasi diperoleh hasil uji ketepatan model sebagai berikut:

Tabel 2. Hasil evaluasi kecocokan model struktural

\begin{tabular}{cccl}
\hline \multicolumn{1}{c}{$\begin{array}{c}\text { GOF } \\
\text { Index }\end{array}$} & $\begin{array}{c}\text { Cut of } \\
\text { Value }\end{array}$ & Hasil & \multicolumn{2}{c}{ Keterangan } \\
\hline Chi-Square & $<110,898$ & 106,327 & $\begin{array}{l}\text { Model Good } \\
\text { Fit }\end{array}$ \\
Probablitity & $>0,050$ & 0,089 & $\begin{array}{l}\text { Model Good } \\
\text { Fit }\end{array}$ \\
CMIN/DF & $<2,000$ & 1,208 & $\begin{array}{l}\text { Model Good } \\
\text { Fit } \\
\text { Model Good }\end{array}$ \\
RMSEA & $<0,080$ & 0,042 & $\begin{array}{l}\text { Fit } \\
\text { Model Good } \\
\text { Fit }\end{array}$ \\
GFI & $>0,900$ & 0,904 &
\end{tabular}

\begin{tabular}{cccl} 
AGFI & $>0,900$ & 0,851 & $\begin{array}{l}\text { Model } \\
\text { Marginal Fit } \\
\text { CFI }\end{array}$ \\
& $>0,900$ & 0,984 & $\begin{array}{l}\text { Model Good } \\
\text { Fit }\end{array}$ \\
\hline
\end{tabular}

Pada Tabel 2. menunjukkan bahwa keseluruhan hasil dari modifikasi model baik.

\section{e. Hasil Pengujian Hipotesis}

Sebuah hubungan kausal dinyatakan signifikan jika nilai critical ratio (C.R.) $>1.96$ dengan tingkat signifikansi $<0,05$. Dengan bantuan aplikasi program AMOS 20 diperoleh hasil estimasi nilai critical ratio model structural. Secara ringkas hasil perhitungan koefisienkoefisien tersebut disajikan dalam tabel berikut:

Tabel 3. Hasil pengujian hipotesis

\begin{tabular}{|c|c|c|c|c|c|}
\hline \multicolumn{3}{|c|}{ Hubungan } & Koefisien Jalur & CR & P-value \\
\hline $\mathrm{X} 1$ & $>$ & $\mathrm{Z}$ & 0,274 & 2,920 & 0,003 \\
\hline $\mathrm{X} 2$ & $>$ & Z & 0,630 & 5,464 & 0,000 \\
\hline Z & $>$ & Y & 0,364 & 2,502 & 0,012 \\
\hline X3 & $>$ & Y & 0,311 & 2,901 & 0,004 \\
\hline $\mathrm{X} 4$ & $>$ & Y & 0,253 & 2,232 & 0,026 \\
\hline
\end{tabular}

Pada Tabel 3. menunjukkan bahwa, pengetahuan dan informasi pada label sayur organik memiliki pengaruh yang positif dan signifikan terhadap sikap dan norma subjektif, sikap, persepsi kontrol perilaku juga berpengaruh positif dan signifikan terhadap niat pembelian sayur organik. sehingga, semua hipotesis pada penelitian ini diterima. Berikut merupakan diagram jalur model pengukuran outer model dan inner model sebagaimana pada Gambar 1.

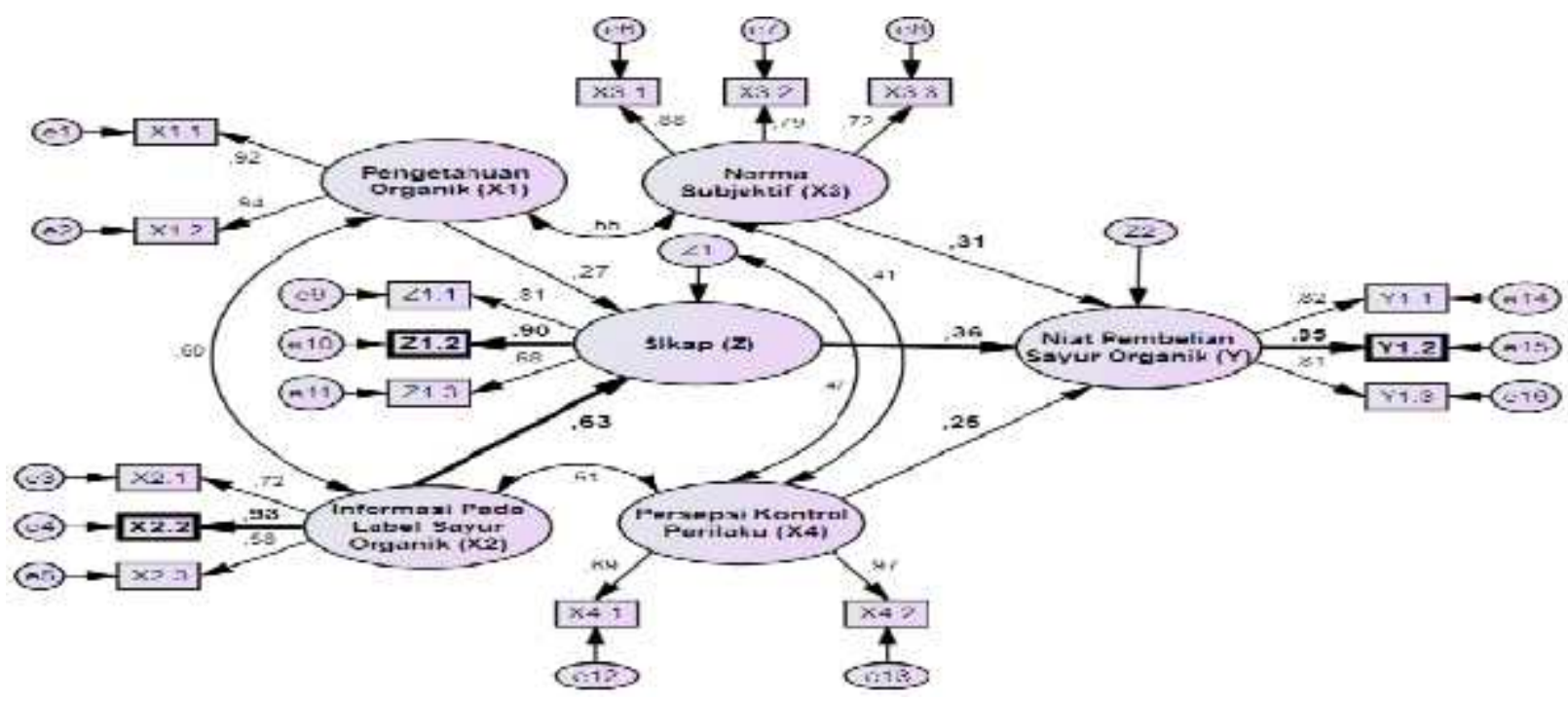

Gambar 1. Diagram Jalur Model Pengukuran Outer Model dan Inner Model 
Pengetahuan organik berpengaruh positif dan signifikan terhadap sikap ibu rumah tangga pada sayur organik. temuan penelitian ini memperkuat hasil penelitian dari (Teng and Wang 2015); (Maichum et al. 2017); (Magistris, Tiziana and Gracia 2008); (Yiridoe, BontiAnkomah, and Martin 2005). Pengetahuan mengenai sayur organik berfungsi sebagai pertimbangan seseorang dalam menentukan sikap terhadap sayur organik (Yiridoe et al. 2005); (Magistris, Tiziana and Gracia 2008). Dengan pengetahuan yang dimiliki tentang sayur organik, maka seseorang akan dengan mudah mengevaluasi dan membandingkan manfaat yang diperoleh dari sayur organik dibandingkan dengan sayur non-organik seperti dari segi kesehatan, keamanan dan kualitas sayur organik (Magistris, Tiziana and Gracia 2008). Seseorang yang memiliki pengetahuan organik, cenderung memiliki sikap positif terhadap produk organik, dikarenakan terdapat keyakinan bahwa produk organik bermanfaat baginya dari segi kesehatan, dan keamanan.

Informasi pada label sayuran organik berpengaruh positif dan signifikan terhadap sikap ibu rumah tangga pada sayur organik. temuan penelitian ini memperkuat hasil penelitian dari (Teng and Wang 2015)menunjukkan bahwa pelabelan organik memberikan sinyal berkualitas kepada konsumen, dan merupakan alat penting untuk membantu mereka mengidentifikasi dan mengembangkan sikap positif terhadap makanan organik. (Kim and Chung 2011) berpendapat bahwa label pangan merupakan alat komunikasi yang digunakan untuk memenuhi kebutuhan informasi.

Sikap dan norma subjektif berpengaruh positif dan signifikan terhadap niat pembelian sayur organik. Temuan ini mendukung hasil. penelitian yang dilakukan oleh (Magistris, Tiziana and Gracia 2008); (Maichum et al. 2017); (Tarkiainen and Sundqvist 2005); (Kim and Chung 2011); (Kalafatis et al. 1999); (Dean et al. 2008); (Teng and Wang 2015) Menyatakan bahwa semakin positif sikap seseorang terhadap sayur organik maka semakin tinggi niat pembelian seseorang terhadap sayur organik. Begitu pula norma subjektif, kelompok referensi menjadi stimulus seseorang dalam merespon niat pembelian pangan organik dan anggota keluarga merupakan kelompok acuan primer yang paling berpengaruh dalam mempengaruhi niat pembelian dikarenakan paling dekat dengan individu.
Persepsi kontrol perilaku terhadap niat pembelian sayur organik positif dan signifikan. Temuan ini mendukung hasil penelitian yang dilakukan oleh (Kim and Chung 2011); (Maichum et al. 2017); (Kalafatis et al. 1999); (Dean et al. 2008); (Teng and Wang 2015) yang menyatakan bahwa dalam menampilkan niat beli pangan organik, konsumen biasanya mempertimbangkan faktor-faktor yang mempermudah atau mempersulit seseorang dalam membeli pangan organik seperti ketersedian di pasar dan juga kemampuan dalam membelinya.

\section{Kesimpulan}

Berdasarkan hasil analisis data dan pembahasan hasil penelitian yang dilakukan oleh peneliti, maka kesimpulan pada penelitian ini yaitu pengetahuan dan informasi pada label sayur organik dapat mendorong sikap positif ibu rumahtangga terhadap sayur organik. tiga variabel dari theory planned behavior yaitu sikap, norma subjektif dan persepsi kontrol perilaku teruji berpengaruh positif dan signifikan terhadap niat pembelian sayur organik di kota Malang.

Saran pada penelitian ini pertama yaitu Pemerintah, produsen, ritel dan lembaga-lembaga terkait dengan sayur organik dapat bekerjasama dalam memberikan edukasi mengenai input, proses, ciri-ciri sayur organik, serta mengenai kualitas dan manfaat yang diberikan sayur organik bagi kesehatan dan kelesarian lingkungan jangka panjang untuk mendorong sikap positif terhadap sayur organik dengan cara penyuluhan maupun sosialisasi pada kegiatan PKK ditiap wilayah. Kedua, Informasi pelabelan yang cukup dan dapat diandalkan adalah hal penting untuk penciptaan sikap positif terhadap sayur organik. oleh karena itu produsen sayur organik dapat menyajikan label organik yang mengandung informasi yang jelas dan dapat mewakili kualitas kepada konsumen, seperti mencantumkan merek, isi, persentase kandungan bahan organik, mineral, vitamin, nomor sertifikasi dan logo untuk menstimulasi sikap positif.

Saran ketiga pemasar perlu mendekati kelompok referensi keluarga atau memperhatikan kelompok referensi sebagai bagian dari target komunikasi pemasaran, anggota keluarga merupakan kelompok acuan primer yang paling berpengaruh dalam pembelian pangan organik. Meskipun pembelian dilakukan oleh individu, keputusan pembelian sangat mungkin dipengaruhi oleh anggota lain dalam keluarga. 
Saran kepada penelitian selanjutnya agar melakukan penelitian yang sama dengan menambahkan variabel lain, seperti kesadaran kesehatan, kesdaran lingkungan dan keseimbangan hidup dalam membentuk sikap positif konsumen terhadap produk organik.

\section{Daftar Pustaka}

Ajzen, Icek. 2008. "Measuring Oral Health Behaviour in Flemish Health Care Workers: An Application of the Theory of Planned Behaviour." Community Dental Health 25(2):107-14.

AOI. 2015. "Pertumbuhan Pangan Organik Nasional Hanya 5 Persen."

AOI. 2017. Statistik Pertanian Organik Indonesia 2016. Vol. 39.

Bourlakis, Michael A. and Paul W. H. Weightman. 2011. Food Supply Chain Management.

Chan, Ricky Y. K. 2001. "Determinants of Chinese Consumers ' Green Purchase Behavior."18(April 2001):389-413.

Dean, Moira, Monique M. Raats, and Richard Shepherd. 2008. "Moral Concerns and Consumer Choice of Fresh and Processed Organic Foods." Journal of Applied Social Psychology 38(8):2088-2107.

Ferdinand. 2005. Metode Penelitian Manajemen: Pedoman Penelitian Untuk Skripsi, Tesis Dan Disertai Ilmu Manajemen. 5th ed. semarang.

IFOAM. 2017. The Word of Organic Agriculture Statistic and Emerging Trends 2017. Jerman: FIBL.

Kalafatis, Stavros P., Michael Pollard, Robert East, and Markos H. Tsogas. 1999. Green Marketing and Ajzen's Theory of Planned Behaviour: A Cross-Market Examination. Vol. 16.

Kim, Hee Yeon and Jae Eun Chung. 2011. "Consumer Purchase Intention for Organic Personal Care Products." Journal of Consumer Marketing 28(1):40-47.

Magistris, Tiziana and Gracia, Azucena. 2008. "The Decision to Buy Organic Food Products in Southern Italy." Birtish Food Journal 110(9):929-47.
Maichum, Kamonthip, Surakiat Parichatnon, and Ke-chung Peng. 2017. "Developing An Extended Theory Of Planned Behavior Model To Investigate Consumers , Consumption Behavior Toward Organic Food: A Case Study In Thailand." International Journal of Scientific \& Technology Research 6(01):72-80.

Mayrowani, Henny. 2016. "Pengembangan Pertanian Organik Di Indonesia." Forum Penelitian Agro Ekonomi 30(2):91-108.

Priambodo, Lutfhan Hadhi and Mukhamad Najib. 2014. "Analisis Kesediaan Membayar ( Willingness to Pay ) Sayuran Organik Dan Faktor-Faktor Yang Mempengaruhinya." Jurnal Manajemen Dan Organisasi 5(1):1-14.

Solimun. 2003. "Multivariate Analysis Structural Equation Modelling (SEM) Lisrel Dan Amos." Fakultas Matematika Dan Ilmu Pengetahuan.

Syukur, Muhamad. 2016. "Pengembangan Pertanian Organik Di Indonesia." IPB Press.

Tarkiainen, Anssi and Sanna Sundqvist. 2005. "Subjective Norms, Attitudes and Intentions of Finnish Consumers in Buying Organic Food." British Food Journal 107(11):808-22.

Teng, Chih Ching and Yu Mei Wang. 2015. "Decisional Factors Driving Organic Food Consumption: Generation of Consumer Purchase Intentions." British Food Journal 117(3):1066-81.

Yiridoe, Emmanuel K., Samuel Bonti-Ankomah, and Ralph C. Martin. 2005. "Comparison of Consumer Perceptions and Preference toward Organic versus Conventionally Produced Foods: A Review and Update of the Literature." Renewable Agriculture and Food Systems 20(04):193-205. 